\title{
Wet Soil Redox Chemistry as Affected by Organic Matter and Nitrate
}

\author{
Duane T. Gardiner, Stephanie James \\ Texas A\&M University-Kingsville, Kingsville, USA \\ Email: duane.gardiner@tamuk.edu
}

Received September 12, 2012; revised October 13, 2012; accepted October 23, 2012

\begin{abstract}
Wet soil microcosms were established to determine effects of organic matter and nitrate additions on microbial respiration and redox potentials. Organic matter $(1 \%)$ and nitrate $(100 \mathrm{ppm}$ and $200 \mathrm{ppm})$ treatments were applied in factorial combination. Soil $\mathrm{pH}$, redox potential, and $\mathrm{CO}_{2}$ emissions were measured. Data were analyzed by ANOVA for repeated measures and separately by sampling day. Addition of organic matter significantly $(\mathrm{P}<0.05)$ and consistently increased $\mathrm{CO}_{2}$ emissions and decreased redox potentials. On Day 42 nitrate significantly $(\mathrm{P}<0.05)$ increased redox values. This study indicates a tendency for organic matter to decrease soil redox potential both in absolute terms and relative to the suboxic-anoxic boundary. Our findings portend that additions of organic matter may quickly and markedly decrease soil redox potentials and increase $\mathrm{CO}_{2}$ emissions in wetlands, whereas additions of nitrate may have complex and sporadic effects on redox potentials.
\end{abstract}

Keywords: Oxidation; Reduction; Wetlands; Carbon Dioxide Emission

\section{Introduction}

Microbial respiration in the soil, accomplished by linking oxidation and reduction half-reactions, directly impacts the redox potential (Eh) of soil-water systems. Soil redox potential affects, and is affected by, many attributes of the ecosystem. In soil the primary electron donor for oxidation half-reactions is organic matter. In aerobic soil the prevailing electron acceptor for reduction half-reactions is molecular oxygen $\left(\mathrm{O}_{2}\right)$. Unlike higher organisms, microbial populations can use electron acceptors less susceptible to reduction than $\mathrm{O}_{2}$, especially in environments where $\mathrm{O}_{2}$ is absent. Where microbes and organic matter are abundant, the absence of $\mathrm{O}_{2}$ (i.e., an anaerobic condition) leads to the reduction of other substances, creating a low redox potential as expressed in units of millivolts or by the term pe implying the negative logarithm of concentration of electrons in search of an electron acceptor.

Electron acceptors are generally reduced in the following order as redox potentials decline: $\mathrm{O}_{2}, \mathrm{NO}_{3}^{-}$, $\mathrm{Mn}^{4+}, \mathrm{Fe}^{3+}, \mathrm{SO}_{4}^{2-}$ [1]. Oxic soils (also termed normal, oxidized, and aerobic) are those soils with high redox potentials indicating that $\mathrm{O}_{2}$ is present. Anoxic soils (also termed reduced, and water-logged) are soils in which $\mathrm{O}_{2}$ has been reduced and is absent, as are sulfate $\left(\mathrm{SO}_{4}^{2-}\right)^{2}$ and other less preferable electron acceptors. Suboxic soils (also termed wet but not water-logged) are those having intermediate redox potentials in which $\mathrm{O}_{2}$ is ab- sent but sulfate has not been completely reduced. A concept used to delineate anoxic and suboxic soils is the pe-pH boundary between oxidized and reduced sulfur, as described by Baas Becking et al. [2] and modified by Sposito [1] and Essington [3]. This boundary between suboxic and anoxic conditions is described by the equation: $\mathrm{pe}=9-\mathrm{pH}$.

Nitrate $\left(\mathrm{NO}_{3}^{-}\right)$is a particularly effective electron accepter in the absence of $\mathrm{O}_{2}$, and can presumably mitigate the reduction of sulfate and chemicals less preferable as electron acceptors, preventing very low redox potentials. Whitmire and Hamilton [4] demonstrate an increase in sulfate coinciding with denitrification, suggesting that the presence of nitrate for an electron acceptor may alleviate sulfate reduction or encourage sulfur oxidation. A decrease in wet soil redox potential has been linked to the loss of nitrate [5]. The phenomenon of denitrification occurs when nitrate, functioning as an electron acceptor, is reduced to gaseous nitrogen. The extent to which denitrification occurs depends upon many environmental factors, including the quality of the carbon in the system [6], the relation between organic $\mathrm{N}$ mineralization and the presence of inorganic electron acceptors [7], and competing fates of nitrate [8]. The effects of nitrate on soil redox potential are intrinsically complex. The presence of three soil factors, organic matter, $\mathrm{O}_{2}$, and nitrate, could strongly influence microbial respiration and soil redox potential. 
Wetlands, either natural or constructed, are used for nitrogen removal from water catchments. The effectiveness of wetlands for nitrate attenuation has been assessed in lab [9], mesocosm [10], and field studies [11], with differing results.

Also, wetlands are often constructed in locations where they did not formerly exist to compensate for the loss of wetlands elsewhere. As wetlands come into existence, one might well ask whether or not wetland functions have also come into existence, or has the process only created lands that are wet [12]. Answers to such questions hinge on the chemistry, biology, and hydrology of a site. Moreover, legally recognized diagnostic characteristics for wetlands in the United States [13] include the presence of hydric soils, i.e., soils with anaerobic conditions. Yet some soils, natural or otherwise, can be inundated for long periods of time while maintaining high redox potentials, indicating a lack of anaerobic conditions. Soil redox potential influences many processes of practical importance, such as the degradation of pesticides [14]. Therefore understanding the nature of both constructed and natural wetlands requires an understanding of the factors associated with aerobic and anaerobic conditions as indicated by measurements of soil redox potential.

The primary objective of this study was to determine if, and to what extent, organic matter addition would increase respiration in wet soils therefore consuming $\mathrm{O}_{2}$ and decreasing redox potentials. If redox potentials were reduced by organic matter, the secondary objective would be to determine whether or not nitrate would mitigate those effects, either in an absolute sense or in relation to the wet-waterlogged (suboxic-anoxic) boundary.

\section{Materials and Methods}

Experimental units were 18 wet soil microcosms consisting of 1-liter opaque bottles, each containing $1.0 \mathrm{~kg}$ of soil collected from a seasonally wet site of the Aransas National Wildlife Refuge in southern coastal Texas, USA. The soil was excavated from the upper $30 \mathrm{~cm}$ of a probable Mustang soil (Mixed, hyperthermic Typic Psammaquents) mapped as the Galveston-Mustang Association [15]. The soil contained $89.5 \%$ sand, $3.8 \%$ clay, $6.2 \%$ silt, $0.6 \%$ organic matter, $2.6 \mathrm{~g} \mathrm{~kg}^{-1}$ total nitrogen, and $31 \mathrm{mg}$ $\mathrm{kg}^{-1}$ nitrate.

Experimental treatments were applied in a $2 \times 3$ factorial combination of 0 and $1 \%$ organic matter additions $(0$ and $\left.10 \mathrm{~g} \mathrm{~kg}^{-1}\right)$; and 0,100 , and $200 \mathrm{ppm}$ nitrate additions (0, 100, and $\left.200 \mathrm{mg} \mathrm{kg}^{-1}\right)$, replicated three times. The organic matter added was dried Burmudagrass containing $1.33 \mathrm{mg} \mathrm{kg}^{-1}$ nitrogen. Nitrate was added as $\mathrm{NaNO}_{3}$. The treatment combination that included neither organic matter nor nitrate constituted the control. Each microcosm was randomly assigned to a treatment. Soils were main- tained in a wet condition with a few mm of water covering the surface, and incubated in a growth chamber held a $30^{\circ} \mathrm{C}$ with 11 hours of simulated sunlight.

Electrode measurements of $\mathrm{pH}$ and redox potential were taken at 14-day intervals for a period of 112 days. Redox values were determined using a calomel electrode, then adjusted to standard Eh values relative to a hydrogen electrode by adding $245 \mathrm{mV}$ to the calomel-electrode values [16]. Redox values relative to the sloping line separating suboxic and anoxic soils were calculated by determining the difference between the measured redox value and the threshold redox value corresponding to the soil $\mathrm{pH}$, given that $\mathrm{pe}=9-\mathrm{pH}$, and that Eh expressed in millivolts $=59.16$ pe.

Carbon dioxide emissions were determined by measuring $\mathrm{CO}_{2}$ concentrations in the headspace above each soil [17] on day 1 , then again on days $8,15,22,29$, and 70. Tops of the containers were open during incubation, but sealed for $10 \mathrm{~min}$ for $\mathrm{CO}_{2}$ sampling, at which time $100 \mathrm{~mL}$ samples were collected from the $415 \mathrm{~mL}$ headspace using a Sensidyne gas detection pump (Sensidyne Inc., Clearwater, FL) connected in series to an RAE gas detection tube (RAE Systems Inc., Sunnyvale, CA).

Effects of organic matter and nitrate on dependent variables $\mathrm{CO}_{2}$ and redox potential were analyzed by ANOVA for a repeated measures design. Also, separate data analyses for each individual sampling day were conducted by ANOVA for a factorial design [18].

\section{Results}

Tables 1 and 2 show $P$ values indicating significance of treatment effects. We considered any $\mathrm{P}$ value less than 0.05 to be significant. Results from the analysis of variance for repeated measures of the dependent variables $\mathrm{CO}_{2}$, redox potential, and relative redox potential are presented in Table 1. For $\mathrm{CO}_{2}$, organic matter main effects and the organic matter interaction with time were significant. Nitrate did not significantly affect $\mathrm{CO}_{2}$ levels. For redox values and relative redox values, interactions between time and organic matter, and between nitrate and time, were very highly significant $(\mathrm{P}<0.001)$. Also for both redox and relative redox values, the main effects of organic matter were very highly significant $(\mathrm{P}<0.001)$ but main effects of nitrate were not significant $(\mathrm{P}>0.05)$. Because of the interactions with time (i.e., sampling day) in a temporally repeated measures design, data were also analyzed for each individual sampling day. Table 2 indicates results of analysis of variance on redox values and relative redox values performed for individual sampling days.

Microbial respiration as measured by $\mathrm{CO}_{2}$ evolution (Figure 1) increased significantly in response to additions of organic matter as measured on Days 8, 15, 22, and 
Table 1. $P$ values for temporally repeated measures of carbon dioxide emissions $\left(\mathrm{CO}_{2}\right)$, soil redox potential (redox), and soil redox potential relative to the suboxic-anoxic boundary (relative redox). Variables were nitrate $(\mathrm{N})$, organic matter $(\mathrm{O})$ and time $(\mathrm{T})$.

\begin{tabular}{ccccccc}
\hline & \multicolumn{2}{c}{$\mathrm{CO}_{2}$} & \multicolumn{2}{c}{ Redox } & \multicolumn{2}{c}{ Relative Redox } \\
\hline Source & df & P value & df & P value & df & P value \\
\hline $\mathrm{N}$ & 2 & 0.281 & 2 & 0.143 & 2 & 0.094 \\
$\mathrm{O}$ & 1 & $<0.001$ & 1 & $<0.001$ & 1 & $<0.001$ \\
$\mathrm{~N} \times \mathrm{O}$ & 2 & 0.374 & 2 & 0.384 & 2 & 0.355 \\
$\mathrm{~T}$ & 5 & 0.011 & 8 & $<0.001$ & 8 & $<0.001$ \\
$\mathrm{~N} \times \mathrm{T}$ & 10 & 0.769 & 16 & $<0.001$ & 16 & $<0.001$ \\
$\mathrm{O} \times \mathrm{T}$ & 5 & 0.028 & 8 & $<0.001$ & 8 & $<0.001$ \\
$\mathrm{~N} \times \mathrm{O} \times \mathrm{T}$ & 10 & 0.839 & 16 & 0.103 & 16 & 0.120 \\
\hline
\end{tabular}

Table 2. $P$ values for effects of nitrate $(\mathrm{N})$ and organic matter $(\mathrm{O})$ on soil redox potential (redox) and soil redox potential relative to the suboxic-anoxic boundary (relative redox) as determined by analysis of variance for a factorial design. On no sampling day was the $\mathrm{N} \times \mathrm{O}$ interaction significant.

\begin{tabular}{ccccc}
\hline & \multicolumn{2}{c}{ Redox } & \multicolumn{2}{c}{ Relative Redox } \\
\hline Sampling Day & $\mathrm{N}$ & $\mathrm{O}$ & $\mathrm{N}$ & $\mathrm{O}$ \\
\hline 1 & 0.940 & 0.063 & 0.543 & 0.046 \\
14 & 0.098 & $<0.001$ & 0.016 & 0.004 \\
28 & 0.215 & $<0.001$ & 0.393 & $<0.001$ \\
42 & 0.042 & $<0.001$ & 0.010 & 0.001 \\
56 & 0.093 & $<0.001$ & 0.245 & 0.003 \\
70 & 0.151 & $<0.001$ & 0.226 & $<0.001$ \\
84 & 0.075 & $<0.001$ & 0.076 & $<0.001$ \\
98 & 0.137 & 0.004 & 0.191 & 0.006 \\
112 & 0.274 & $<0.001$ & 0.216 & $<0.001$ \\
\hline
\end{tabular}

29. Because neither nitrate main effects nor nitrate $\times$ organic matter interactions were significant on any sampling day, data from nitrate treatments were pooled such that organic matter effects presented in Table 1 include averages of all treatments with the organic matter addition vs all treatments without it.

Organic matter additions consistently produced a strong negative effect on soil redox values, with highly significant results observed on all days after Day 1 (Table 2; Figure 2). Nitrate did not significantly affect soil redox values except on Day 42, when redox values were higher for the $100 \mathrm{ppm}$ nitrate treatment than for the control. No significant interactions between nitrate and organic matter were observed.

\section{Discussion}

The data strongly support the hypothesis that adding soil organic matter will decrease soil redox potentials. Furth-

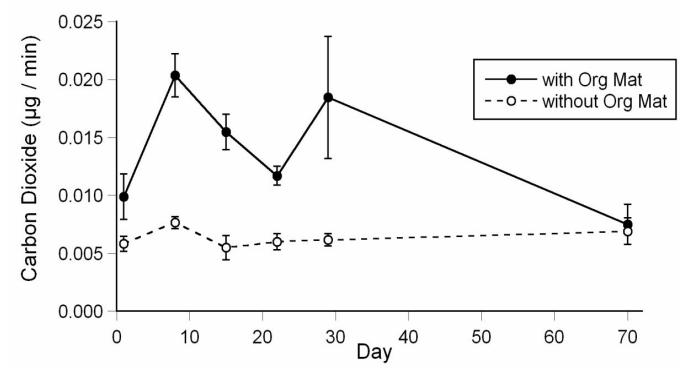

Figure 1. Carbon dioxide emitted from 1.0-kg wet soil microcosms. Values are means of all treatments either with or without a $1 \%$ addition of organic matter. Vertical bars indicate standard errors of the means.

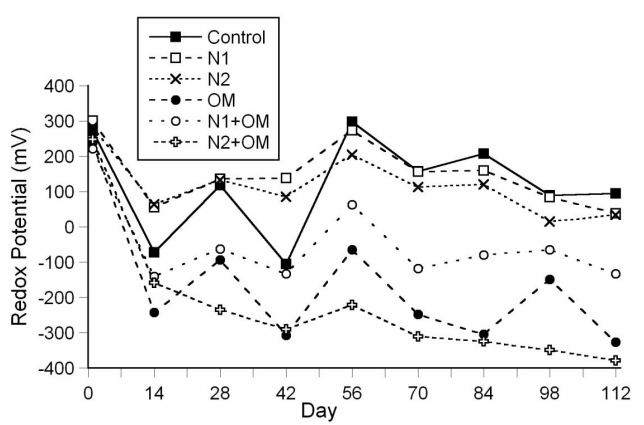

Figure 2. Mean soil redox potentials as affected by organic matter and nitrate. Treatments levels were $100 \mathrm{ppm}$ nitrate (N1), 200 ppm nitrate (N2), and 1\% organic matter (OM).

ermore, the control treatment having native levels of organic matter and nitrate resulted in intermediate redox potentials through Day 42, after which it produced the highest redox values of all treatments. This further supports the hypothesis that the negative impact on redox values was caused by the organic matter addition, not by the native organic matter in the soil.

This study uniquely measured redox potential relative to the $\mathrm{pH}$-dependent boundary line separating suboxic and anoxic soils (Figure 3). Effects of organic matter were significant on every sampling day, whereas effects of nitrate were significant on Days 14 and 42 only (Table 2). Interactions between nitrate and organic matter were not significant on any sampling day. Redox values relative to the suboxic-anoxic boundary can be more telling than absolute redox values because of their relation to actual events or reactions. In suboxic soil sulfate and perhaps other species ranging between $\mathrm{O}_{2}$ and sulfate in redox susceptibility remain in their oxidized state; whereas in anoxic soil sulfate is absent, having been reduced to sulfide or other forms of reduced sulfur. As one might expect, many data points in Figure $\mathbf{3}$ are in close proximity to the boundary line, suggesting that for these soils sulfate may be reducing but not completely reduced. With the disappearance of sulfate, soil redox potentials 


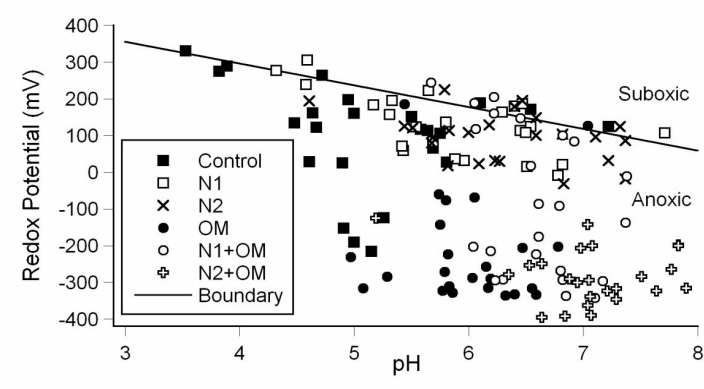

Figure 3. Soil redox potential relative to the boundary separating suboxic and anoxic soils. The boundary is a function of pH. Treatments levels were $100 \mathrm{ppm}$ nitrate (N1), 200 ppm nitrate (N2), and $1 \%$ organic matter (OM).

can fall appreciably below the boundary line, as was observed in most measurements here.

The findings raise the question of why redox potentials relative to the suboxic-anoxic boundary were somewhat more strongly influenced by nitrate than were absolute redox values. Denitrification rates have long been known to be inhibited by acidic soil; therefore denitrification may have occurred to a lesser extent where $\mathrm{pH}$ values were lower. However, we postulate that a second explanation may also apply, i.e., that denitrification may have produced the mildly alkaline reaction product bicarbonate as suggested Equation (1) [19].

$$
5 \mathrm{CH}_{2} \mathrm{O}+4 \mathrm{NO}_{3}^{-} \rightarrow 2 \mathrm{~N}_{2}+4 \mathrm{HCO}_{3}^{-}+\mathrm{CO}_{2}+3 \mathrm{H}_{2} \mathrm{O} \text {. }
$$

Figure 3 indicates that the combination of $\mathrm{N}$ plus organic matter generally tended to increase $\mathrm{pH}$; and illustrates that as $\mathrm{pH}$ increases the boundary line slopes downward. With all other factors remaining constant, a treatment causing a slight elevation in $\mathrm{pH}$ would increase redox value relative to the boundary line, and would tend to shift equilibria between reduced and oxidized sulfur toward the oxidized state.

Only for Days 14 and 42 did the results support the hypothesis that nitrate would mitigate the impact of organic matter. Because denitrification is one of many possible fates of nitrate, this result was not unexpected. Studies of $\mathrm{N}$ attenuation in wetlands reveals a wide range of results, including $100 \%$ nitrate and $69 \%$ total $\mathrm{N}$ attenuation [11], $13 \%$ to $73 \%$ nitrate attenuation, [9], and $51 \%$ total $\mathrm{N}$ attenuation [20]. Investigators [10,21] show generally positive correlations between nitrate reduction and soil organic matter. Matheson et al. [8] found that in unplanted wetland microcosms $49 \%$ of nitrate nitrogen was reduced to ammonium, $29 \%$ was denitrified, and $22 \%$ was immobilized. Adding to the complexities of quantifying denitrification in wetlands is its tendency to occur simultaneously or sequentially with nitrogen recycling [22]. Whitmire and Hamilton [4] observed nitrate depletion within 5 to 20 hours, leading to the speculation for the present study that added nitrate might have already been reduced to another form when the first redox reading was taken, perhaps to cycle back as nitrate later in the study, such as on day 42 when nitrate treatment effects were surprisingly significant.

In conclusion, this study of wet soil microcosms described the effects of organic matter and nitrate on respiration, redox potentials, and relative redox potentials (i.e., relative to the suboxic-anoxic boundary). Relative redox potentials are of particular relevance because they provide an indication of the effect of a factor on electron acceptors having lesser susceptibility to reduction than $\mathrm{O}_{2}$ but greater than sulfate. We found that an organic matter addition of $1 \%$ markedly decreased the redox potential of wet soil both in the absolute sense and relative to the suboxic-anoxic boundary. On two sampling days nitrate raised redox potentials relative to the suboxicanoxic boundary. Our findings suggest that adding organic matter to a wetland may quickly and markedly decrease soil redox potential and increase $\mathrm{CO}_{2}$ emission. Our findings offer little information from which a response to nitrate could be predicted, but rather serve to corroborate previous descriptions of the complex nature of nitrate in wetlands.

\section{Acknowledgements}

We thank the USDA Natural Resources Conservation Service for funding this project.

\section{REFERENCES}

[1] G. Sposito, "The Chemistry of Soils," Oxford University Press, New York, 1989.

[2] L. G. M. Baas Becking, L. R. Kaplan and D. Moore, "Limits of the Natural Environment in Terms of $\mathrm{pH}$ and Oxidation-Reduction Potentials," Journal of Geology, Vol. 68, No. 3, 1960, pp. 224-284.

[3] M. E. Essington, "Soil and Water Chemistry: An Integrative Approach," CRC Press, Boca Raton, 2004.

[4] S. L. Whitmire and S. K. Hamilton, "Rapid Removal of Nitrate and Sulfate in Freshwater Wetland Sediments," Journal of Environmental Quality, Vol. 34, No. 6, 2005, pp. 2062-2071.

[5] T. Mansfeldt, "Redox Potential of Bulk Soil and Soil Solution Concentration of Nitrate, Manganese, Iron, and Sulfate in Two Gleysols," Journal of Plant Nutrition and Soil Science, Vol. 167, No. 1, 2004, pp. 7-16.

[6] N. P. Hume, M. S. Fleming and A. J. Horne, "Denitrification Potential and Carbon Quality of Four Aquatic Plants and Wetland Microcosms," Soil Science Society of America Journal, Vol. 66, No. 5, 2002, pp. 1706-1712.

[7] J. R. White and K. R. Reddy, "Influence of Selected Inorganic Electron Acceptors on Organic Nitrogen Mineralization in Everglade Soils," Soil Science Society of America Journal, Vol. 65, No. 3, 2001, pp. 941-948. 
[8] F. E. Matheson, N. L. Nguyen, A. B. Cooper, T. P. Burt and D. C. Bull, "Fate of ${ }^{15} \mathrm{~N}-$ Nitrate in Unplanted, Planted and Harvested Riparian Wetland Soil Microcosms," Ecological Engineering, Vol. 19, No. 4, 2002, pp. 249-264.

[9] T. E. Davidsson and M. Ståhl, "The Influence of Organic Carbon on Nitrogen Transformations in Five Wetland Soils," Soil Science Society of America Journal, Vol. 64, No. 3, 2000, pp. 1129-1136.

[10] M. R. Burchell II, R. W. Skaggs, C. R. Lee, S. Broome, G. M. Chescheir and J. Osborne, "Substrate Organic Matter to Improve Nitrate Removal in Surface-Flow Constructed Wetlands," Journal of Environmental Quality, Vol. 36, No. 1, 2007, pp. 194-207.

[11] X. Zhang, S. E. Feagley, J. W. Day, W. H. Conner, I. D. Hesse, J. M. Rybczyk and W. H. Hudnall, "A Water Chemistry Assessment of Wastewater Remediation in a Natural Swamp," Journal of Environmental Quality, Vol. 29, No. 6, 2000, pp. 1960-1968.

[12] National Research Council, "Compensating for Wetland Losses under the Clean Water Act," National Academy Press, Washington, 2001.

[13] Wetland Training Institute, "Field Guide for Wetland Delineation, 1987 Corps of Engineers Manual," Wetland Training Institute, Glenwood, 2002.

[14] R. D. DeLaune, I. Devai, C. Crozier and C. W. Lindau, "The Influence of Soil Redox Conditions on Atrazine Degradation in Wetlands," Agriculture Ecosystems and Environment, Vol. 66, No. 1, 1997, pp. 41-46.

[15] United States Department of Agriculture-Soil Conservation Service, "Soil Survey of San Patricio and Aransas
Counties, Texas," US Government Printing Office, Washington, 1979.

[16] W. H. Patrick, R. P. Gambrel and S. P. Faulkner, "Redox Measurements of Soil," In: D. L. Sparks, et al., Eds., Methods of Soil Analysis, Soil Science Society of America, Madison Wisconsin, 1996, pp. 1155-1273.

[17] United States Department of Agriculture, "Soil Quality Test Kit Guide," US Government Printing Office, Washington, 1998.

[18] Analytical Software, "Statistix 8 Users Manual," Analytical Software, Tallahassee, 2003.

[19] L. J. Puckett and T. K. Cowdery, "Transport and Fate of Nitrate in a Glacial Outwash Aquifer in Relation to Ground Water Age, Land Use Practices, and Redox Processes," Journal of Environmental Quality, Vol. 31, No. 3, 2002, pp. 782-796.

[20] M. Healy and A. M. Cawley, "Nutrient Processing Capacity of a Constructed Wetland in Western Ireland," Journal of Environmental Quality, Vol. 31, No. 5, 2002, pp. 1739-1747.

[21] P. J. Bohlen and S. M. Gathumbi, "Nitrogen Cycling in Seasonal Wetlands in Subtropical Cattle Pastures," Soil Science Society of America Journal, Vol. 71, No. 3, 2007, pp. 1058-1065.

[22] L. J. Lund, A. J. Horne and A. E. Williams, "Estimating Denitrification in a Large Constructed Wetland Using Stable Nitrogen Isotope Ratios," Ecological Engineering, Vol. 14, No. 1-2, 2000, pp. 67-76. 